\title{
Vom mehrstimmigen Choral-Satz und Liedmotette zum Generalbaßlied - das Repertoire der handschriftlichen lutherischen Chorbücher des 17. Jahrhunderts aus Oberungarn
}

\section{From the More-part Choral Composition and Choral Motet to the Figured-bass Hymn Setting - the Repertory from the Manuscript Lutheran Choral Books of 17th Century from Upper Hungary}

Peter Ruščin / peter.ruscin@savba.sk

Institut of Musicology, Slovak Academy of Sciences Bratislava, SK

\begin{abstract}
The lutheran manuscript Choral Books from the 17th Century preserved in the territory of Slovakia contain a lot of simple polyphonic Chants and Hymns, especially with German, but also Latin, Hungarian and Czech texts. Almost all of preserved manuscripts comes from Upper Hungary (contemporary Eastern Slovakia). The repertory of the manuscript sources includes arround 300 polyphonic compositions, mostly german origin. There are ca. 50 compositions from (mostly anonymous) local composers in this sources, from small polyphonic works in the traditional style of choral motet or metrical hymn with cantus firmus in discant to spiritual song with figured bass. This various styles of hymn setting stayed in practice in the lutheran churches of Upper Hungary until the Early 18th Century.
\end{abstract}

\section{Key words}

Lutheran church chant, More-part Singing, Manuscript Choral Book, 17th Century, Upper-Hungary, Slovakia 


\section{Einführung}

Die Musikkultur der lutherisch-evangelischen Städte auf dem Gebiet der heutigen Slowakei hat im 17. Jahrhundert relativ hohes Niveau erreicht. Das gilt besonders für die Bergbaustädte von Heptapolitana in der Mittel-Slowakei ${ }^{1}$ und für die Städte von Pentapolitana in der heutigen Ost-Slowakei ${ }^{2}$ und ihre Umgebung, die zum Gebiet des sgn. Oberungarn gehörten. ${ }^{3}$ Die Institutionen der lutherisch-evangelischen Kirchenmusik waren denjenigen der schlesischen oder sächsischen Städte ähnlich. Für die Kirchenmusik war der Kantor verantwortlich. Da hier keine große Städte waren, die Funktion „director musicae“ wurde nich benötigt. Bei der kirchenmusikalischen Aufführungspraxis war der Organist dem Kantoren untergeordnet. ${ }^{4}$ Bei der Aufführung der mehrstimmigen Kirchenmusik in den kleineren Städten nahm der vom Kantor geleitete Schulchor teil. In einigen größeren Städten konnten mit der Hilfe von Stadtmusiker auch die Kantoreien entstanden. ${ }^{5}$ Das Spezifikum waren die nach der ethnischen Zugehörigkeit verteilte Kirchengemeinden, also die deutsche, slowakische und ungarische, die im allgemein ihre eigene Pastoren, Kantoren, manchmal auch Tempel hatten. Bei der üblichen Mehrheit von Deutschen in der Stadtrat hatte natürlich die deutsche Gemeinde eine führende Position.

\section{Das Kirchengesang in dem lutherischen Gottesdienst im ersten Jahrhundert der Reformation}

Eine der frühesten Quellen zur lutherisch-evangelischen liturgischen Ordnung auf dem Gebiet der heutigen Slowakei ist der längst bekannte zeremonielle Nachtrag zum Confessio heptapolitana (1559) Descriptio caremoniarum ecclesiasticarum in civitatibus Montanis Hungariae. ${ }^{6}$ Die Aufführungspraxis der Kirchengesänge ist da ähnlicherweise beschrieben, wie es z.B. in dem allgemein verbreiteten Agend Büchlein für die Pfarherren auff dem Land

1 Banská Belá/Dilln, Banská Bystrica/Neusohl, Banská Štiavnica/Schemnitz, Kremnica/Kremnitz, Lubietová/Libethen, Nová Baňa/Königsberg, Pukanec/Bugganz.

2 Košice/Kaschau, Prešov/Eperies, Sabinov/Seben, Bardejov/Bartfeld und Levoča/Leutschau.

3 Das Gebiet des sgn. Oberungarns war in der Periode zwischen den Jahren 1564 und 1686 im Wesentlichen mit dem Verwaltungsgebiet der Oberungarischen Grenzoberhauptmanschaft, die sein Sitz in Kaschau (Košice) hatte, identisch. Das entspricht ungefähr der heutigen Ostslowakei mit den angrenzenden, von den Türken nicht besetzten Gebiete des heutigen Ungarns, nördlich von dem Fluß Theiß. Das Gebiet der mittelslowakischen Bergbaustädte war in Oberungarn nicht einbegriffen.

4 MATÚŠ, František. Zachariáš Zarevúcky - životné osudy [Zacharias Zarevutius - Lebensgeschichten]. In Zachariáš Zarevúcky (Zarevutius). 400 rokov od narodenia organistu a skladatela. [Zacharias Zarevutius. 400 nach der Geburt des Organisten und Komponisten]. Konferenzbericht. Prešov: Prešovský hudobný spolok Súzvuk, 2005, S. 72-73.

5 Das sgn. Fraternitas Litteratorum in Spišská Nová Ves/Iglo war mindestens seit dem Jahr 1618 tätig. Vgl. PETŐCZOVÁ, Janka. Hudba ako kultúrny fenomén v dejinách Spiša. Bratislava: Ústav hudobnej vedy SAV - Prešovský hudobný spolok Súzvuk, 2014, S. 104-110.

6 Näheres von dieser Quelle vgl. HUDEC, Konštantín. Hudba v Banskej Bystrici do 19. storočia [Die Musik in Banská Bystrica bis zum 19. Jahrhundert]. Liptovský Sv. Mikuláš: Tranoscius, 1941, S. 55-56. 
von Dietrich Veit der Fall ist. Ein Exemplar von Veits Agende (Auflage Nürnberg 1553) ist in der evangelischen Pfarrbibliothek in Leutschau erhalten. Auch andere kirchliche Agenden-Drücke von Wittenberg und Jena wurden auf unserem Gebiet verwendet. ${ }^{7}$ Nach allem diesen liturgischen Ordnungen spielte die lateinische Sprache im lutherischen Gottesdienst zu jener Zeit noch eine wichtige Rolle. ${ }^{8}$ Das Gesang von Kirchenliedern in der Volkssprache war zuerst beim Introitus (das deutsche Psalmlied vom Kantional), vor und nach der Predigt und während des Abendmahls erlaubt. Slowakische Gemeinden hatten an manchen Orten die zweite Auflage von Agenda Cžeská zur Vefügnung, wo auch die tschechische Paraphrasen von Gloria, Credo oder Sanctus einbegriffen sind. ${ }^{9}$

\begin{tabular}{|l|l|l|l|}
\hline & $\begin{array}{l}\text { Descriptio } \\
\text { caeremoniarum }\end{array}$ & Veit: Agend Büchlein & $\begin{array}{l}\text { Agenda bohemica } \\
\text { ('Leipzig 1581) }\end{array}$ \\
\hline Introitus & lateinisch /Psalm deutsch & lateinisch/Psalm deutsch & lateinisch/Kirchenlied \\
\hline Kyrie & lateinisch & lateinisch & $\begin{array}{l}\text { lateinisch/Kyrie-Tropus } \\
\text { tschechisch }\end{array}$ \\
\hline Gloria & lateinisch & lateinisch & tschechische Paraphrase \\
\hline Kollekte & deutsch & deutsch & tschechisch \\
\hline Alleluja & lateinisch & lateinisch/Psalm deutsch & $\begin{array}{l}\text { lateinisch/Motette/ } \\
\text { Kirchenlied }\end{array}$ \\
\hline (Sequenz) & lateinisch & & lateinisch \\
\hline Litanei & & $\begin{array}{l}\text { deutsch } \\
\text { (Knaben - Chor) }\end{array}$ & \\
\hline $\begin{array}{l}\text { Glaubensbe- } \\
\text { kenntnis }\end{array}$ & lateinisch/deutsch & deutsch/lateinisch & tschechisch \\
\hline $\begin{array}{l}\text { (vor/nach der } \\
\text { Predigt) }\end{array}$ & $\begin{array}{l}\text { Kirchenlieder in der Vol- } \\
\text { kssprache }\end{array}$ & & Kirchenlieder \\
\hline Präfation & deutsch & deutsch & tschechisch \\
\hline Sanctus & & lateinisch/deutsch & tschechisch \\
\hline Vaterunser & deutsch & deutsch & tschechisch \\
\hline Abendmahl & $\begin{array}{l}\text { Kirchenlieder in der Volks- } \\
\text { sprache }\end{array}$ & $\begin{array}{l}\text { Agnus Dei (Chor) / Kir- } \\
\text { chenlied }\end{array}$ & Motette / Kirchenlied \\
\hline Bendicamus & lateinisch & lateinisch & lateinisch \\
\hline
\end{tabular}

Tab. 1 Die Sprache der Meßgesänge in den lutherischen Agenden von der 2. Hälfte des 16. Jahrhunderts

7 HULKOVÁ, Marta. Konfesijné zmeny v 16. storočí v Európe a ich vplyv na cirkevnú hudbu na území Slovenska [Konfessionelle Änderungen im 16. Jahrhundert in Europa und ihrer Einfluss auf die Kirchenmusik auf dem Gebiet der Slowakei]. In BUZÁSSYOVÁ, Ludmila - JURÍKOVÁ, Erika - GRUSKOVÁ, Jana (eds.). Ideológia v premenách času v pamiatkach gréckej a latinskej tradície [Die Ideologie in den Zeitwendungen in den Denkmäler der griechischen und lateinischen Tradition]. Bratislava: Univerzita Komenského v Bratislave, 2018, s. 211.

8 RIEDEL, Friedrich W. Lutherischer Gottesdienst und katholische Kirchenmusik. In Gegenreformation und Barock in Mitteleuropa / in der Slowakei. Konferenzbericht. Bratislava: Kabinet für Slawistik der SAW, 2000, S. 65-66.

9 Agenda Cžeská to gest Spis o Ceremonijch a pořádcých Církewnjch... M.D.LXXXI... Wytisstěno w Lipsstě skrze Giřjka Deffnera [Tschechische Agende oder Schrift von den Zeremonien und Kirchenordnungen... 1581... Gedruckt zu Leipzig bei Georg Deffner]. Vgl.: TOBOLKA, Zdeněk Václav. Knihopis českých a slovenských tisků od doby nejstarši až do konce XVIII. Stoleti. [Bibliographie der tschechischen und slowakischen Drucke von den frühesten Zeiten bis zum Ende des 18. Jahrhunderts]. Bd. 2. Praha: Státní tiskárna v Praze, 1936, Nr. 79. 


\section{Die Quellenlage}

Das mehrstimmige Gesang von Kirchenliedern und liturgischen Gesänge in der Volkssprache hat sich in den oberungarischen Städten während der ersten Periode der Reformation nur langsam entwickelt. Das deutsche, insbesondere tschechische und ungarische mehrstimmige liturgische Kirchengesang, ist durch bekannte handschriftliche und gedruckte Quellen der Musikaliensammlung aus Bartfeld und Leutschau oder durch die Kantionaldrucke von Brewers Druckerei zu Leutschau weniger nachweisbar, als durch erhaltene handschriftliche Chorbücher. Diese Chorbücher, die fast alle aus dem oberungarischen Gebiet stammen, stellen ein vom lokalen Kantoren verfertigtes Handbuch des liturgischen Gesangs dar, das mit den Kirchenliedern De Tempore erweitert ist. Es gab verschiedene Typen solcher Chorbücher. Einige können nach ihrer Verteilung eher als Gesangbücher betrachtet werden, so daß sie auch in der bisherigen muskwissenschaftlichen Literatur unter den Namen Gesangbuch oder Kantional bezeichnet wurden. In einem Fall kann man aus typologischer Sicht eindeutig vom Gradual sprechen. In den kleineren zipser Städten waren handschriftliche Chorbücher mit gemischten Repertoire von mehrstimmigen Kirchenlieder, Hymnen, Antiphonen und einfachen Responsorien im 17. Jahrhundert wahrscheinlich allgemain verwendet, und die heutzutage erhaltene Quellen stellen wohl nur ein geringer Teil der ehemaligen von oberungarischen Kantoren verfertigten handschriftlichen Chorbüchern dar. ${ }^{10}$

Die Handschriften aus der 1. Hälfte des 17. Jahrhundert sind uns nur seltsam erhalten. Das Kantional von Banská Bystrica/Neusohl (von Ilona Ferenczi als Kantional von Bestercebánya genannt) aus dem Jahr 1623 stammt eigentlich nicht aus dem Gebiet des Obrungarns im eigenen Sinne, stellt aber die älteste erhaltene Quelle dieser Art aus dem Gebiet der heutigen Slowakei dar. Es sind da etwa 120 mehrstimmige Stücke, davon mehrere Hymnen, Ordinarium-Paraphrasen, Magnificat-Gesänge oder Motetten, Responsorien und Kirchenlieder überwiegend mit lateinischen und deutschen Texten. ${ }^{11}$ $\mathrm{Zu}$ vier mehrstimmigen Gesängen ist es neben lateinischen und deutschen Text auch alttschechische Version und zu einer der vier deutschen Credo-Paraphrasen ein ungarischer Text zugeschrieben. Das Gradual von Prešov/Eperjes (Eperjesi Graduál, 1635) ist eine der wertvollsten Quellen der einstimmigen ungarischen Choral-Gesänge in lutherischer Gottesdienst, unter denen auch 54 mehrstimmige, zum Teil anonyme Stücke, besonders Cantiones, Hymni oder Psalmlieder zu finden sind. ${ }^{12}$ Mehrere fast identische Stücke

10 In diesem Zusammenhang hat sich vor Jahren Marta Hulková geäussert: „Wenn wir die Zahl der evangelichen Gemainschaften an der Wende des 17. und 18. Jahrhunderts in Betracht ziehen, solten wir nicht derei, vier, sondern vierzig-fünfzig ähnlicher Gesangbücher zur Verfügung haben." Vgl. HULKOVÁ, Marta. Evangelische handschriftliche Gesangbücher aus der Spiš (Zips) von der Wende des 17. und 18. Jahrhunderts. In Gegenreformation und Barock in Mitteleuropa / in der Slowakei. Konferenzbericht. Bratislava: Kabinet für Slawistik der SAW, 2000, S. 243.

11 FERENCZI, Ilona. A bestercebányai kancionálé (1623) [Das Kantional von Banská Bystrica]. In MÁNYOKI, János - PINTER, Gábor (eds.). BIVIO Tanulmányok az Evangélikus OrszágSos Könyvtár mühelyéból 2018. Budapest: Evangélikus Országos Gyűjtemény, 2018, s. 32-44.

12 FERENCZI, Ilona (ed.). Graduale Ecclesiae Hungaricae Epperiensis 1635. Musicalia Danubiana 9. Budapest: MTA Zenetudományi Intézet, 1988. 
kann man auch in den späteren zipser Chorbüchern mit deutschem Text finden. ${ }^{13}$ Eine andere Quelle, die leider nur bruchstückweise erhalten ist, stellt das Fragment aus Hôrka/ (St. Andreas, heute ein Teil des Dorfs Hôrka) dar. Die Quelle wurde vorher als Gesangbuch von Hôrka genannt. Ihre Entstehungszeit kann man nach heutiger Kentnisse zwischen den Jahren 1630 und 1650 stellen. Von seinem Inhalt hat Marta Hulková 21 vier-, fünf- oder sechstimmiger Fassungen der tschechischen und lateinischen Kirchenlieder, Cantiones und Paraphrasen teilweise identifiziert. ${ }^{14}$

Aus der Zips-Gebiet sind es uns vier deutsche lutherische Chorbücher aus der 2. Hälfte des 17. Jahrhunderts erhalten. Es handelt sich um folgende handschriftliche Quellen:

- Das Gesangbuch aus Lubica/Leibitz, dessen Hauptteil spätestens in dem 70. Jahren des 17. Jahrhunderts enstand. Die Quelle beinhaltet 190 mehrstimmige Stücke. ${ }^{15}$

- Das Gesangbuch aus Smolnicka Huta/Schmölnitz-Hütte ist nicht komplett erhalten, wir haben nur etwa 132 Seiten von ursprünglichen 366. Seine Entstehungzeit kann dem Gesangbuch aus Lubica ähnlich sein. ${ }^{16}$

- Das Gesangbuch von Nicolaus Simonides aus Vel'ká/Felka ist im relativ guten Zustand „in situ“, im Pfarramt der evangelischen Kirche in Poprad-Vel'ká erhalten. Die Handschrift ist neben dem Gradual von Prešov die einzige Quelle, deren Titelseite erhalten ist, der Titel lautet Himmlischer Engel=Schall oder Gesangbuch... von dem Herren Nicolao Simonides... Anno Domini 1685. Es sind in dem Chorbuch 153 4- bis 6-stimmige Kompositionen mit dem deutschen, bzw. lateinischen Text zu finden. ${ }^{17}$

- Das Gesangbuch von Matthias Kruczay (Kruczay-Gesangbuch), welches jahrelang auf dem katholischen Pfarramt in Lubica aufbewahrt wurde, ist heute, leider, verloren. ${ }^{18}$ Obwohl auf der Titelseite das Jahr 1736 geschrieben ist, kann man voraussetzen, daß die Quelle (wenigstens ihr wesentlicher Teil) einige Jahrzehnte früher entstanden ist. Die Handschrift mit 323 erhaltenen Seiten ist heutzutage leider verschollen und ist nur am Mikrophilm zugänglich. Die Zahl der 4- bis 5-stimmigen Stücke ist $159 .{ }^{19}$

13 FERENCZI, Ilona - HULKOVÁ, Marta. Gemeinsame ein- und mehrstimmige Stücke in dem Gradual von Eperjes und in dem Gesangbuch aus Lubica. Studia Musicologica Academiae Scientiarum Hungaricae, 22, 1980, S. $358-395$.

14 HULKOVÁ, Marta. Spevník z Hôrky a spišské rukopisné spevníky zo 17. a 18. storočia. [Das Gesangbuch aus Hôrka und die Zipser handschriftlichen Gesangbücher aus dem 17. und 18. Jahrhundert.] In Ad honorem Richard Rybarič. Zbornik z muzikologickej konferencie Musicologica historica I. [Ad honorem Richard Rybarič. Konferenzbericht.] Bratislava: Ústav hudobnej vedy SAV, 2011, S. 91-98.

15 HULKOVÁ, Marta. Lubický spevník. [Gesangbuch aus Lubica.] Musicologica Slovaca, 12, 1988, S. $21-102$. 16 HULKOVÁ, 2000, op. cit., S. 245.

17 RUŠČIN, Peter. Die Kirchenlieder aus dem handschriftlichen Gesangbuch Himmlischer Engel-Schall (1685) von Nicolaus Simonides. In PETÓCZOVÁ, Janka (ed.). The Musical Sources of Spiš / Zips and Central Europe. Bratislava: Ústav hudobnej vedy SAV, 2018, S. 66.

18 HULKOVÁ, 2011, op. cit., S. 99.

19 RUŠČIN, Peter. Repertoár Kruczayho spevníka v stredoeurópskom kontexte. [Das Repertoire von Kruczay-Gesngbuch im mitteleuropäischen Kontext]. In Štýlotvorné prvky vo vokálnej a inštrumentálnej hudbe 16. 18. storočia [Stilbildende Elemente in der Vokal- und Instrumentalmusik des 16.-18. Jahrhunderts]. Konferenzbericht. Prešov: Prešovský hudobný spolok Súzvuk, 2003, S. 72-77. 


\section{Die Gattungen des mehrstimmigen Kirchengesangs in den erhaltenen Chorbüchern}

Mehrstimmige Fassungen der liturgischen Gesänge (Antiphonen, Responsorien, Psalmen, Cantica bzw. Ordinarium- und Vaterunser-Paraphrasen) sind nur in etlichen Quellen erhalten. Anderswo (wenn überhaupt) sind sie nur einstimmig notiert, bzw. nur Texte ohne Noten. Die Kirchenlieder inkl. Cantiones und Hymni, meistens in mehrstimmigen Fassung, bilden dagegen das Grundrepertoire von diesen Chorbüchern.

Mehrstimmige Sätze (3- bis 6-stimmige) in den lutherisch-evangelischen handschriftlichen Quellen des 17. Jahrhunderts (ausser Kirchenlieder):

\section{Kantional von Banská Bystrica (1623)}

$\underline{\text { Responsorien }}$

Deo gratias (4), (4)

Et cum Spiritu tuo / Und mit deinem Geist (4), (4), (4), (4), (4), (3)

Amen (4), (4)

Domine ad adjuvandum (4), (4)

Die Braut die wollen wir singen (4)

Habemus a Domino / Das haben wir zu dem Herren (4)

Dignum et justum est / Es ist billich, und ist auch recht (4)

Psalmodie

Dixit Dominus (6), (5)

Laudate Pueri Dominum (4)

Versikulen

Tamquam sponsus/Rorate coeli/Verbum caro/Surrexit Dominus (4)

Verbum caro factum est (4)

Ordinarium-Parphrasen

Allein Gott in der Höh sei Ehr (4), (5)

$\underline{\text { Sequenz }}$

Christ lag in Todes Banden (4)

Vaterunser

Pater in coelis / Mi atyánk (4)

Benedicamus

In Festo Nativitatis (4)

In Festo Parasceve (4)

In Festo Pentecostis (4), (4)

De Sancte Trinitate (4)

Hymnen

Nun komm der Heiden Heiland (4), (3)

Puer natus in Bethlehem / Eind Kind geborn zu Bethlehem (4)

Fit porta Christi pervia / Christi Geburt ist offenbar (4) 
O lux beata Trinitas (3)

Tu tuo laetos famulos tropheo (4)

Spiritus Sancti gratia / Des heligen Geistes reiche Gnad (4), (6)

Magnificat

Denn er hat seine elende Magd angesehen (4)

Denn er hat die Niedrigkeit (5, Tonus 5 - David Thusius)

\section{Gradual von Prešov (1635)}

$\underline{\text { Hymnus }}$

Gyermek születék Betlehemben (4)

Litaneien - Vaterunser

Oh Menyei Atyank - Tekincz keg'essen mi reánk (4)

$\underline{\text { Passion (Turbae) }}$

Secundum Matthaeum (4)

Secundum Johannem (4)

Fragment von Hôrka (ca. 1630-1650)

Hymnus

Puer natus [in Bethlehem] (5)

Ordinarium-Paraphrasen

Kyrie: Hospodine dob... (4)

Otce toho wssemohuceho stworitele nebe (5)

Vaterunser

Otče náš jenž v nebi bydlís (4)

\section{Gesangbuch aus Lubica}

Versikulen

Rorate Coeli de super / Träufet ihr Himmel von oben herab (4)

Verbum caro factum est (4)

Psalmodie

1.-8. Tonus, 9. Tonus (peregrinus) (4)

\section{$\underline{\text { Responsorien }}$}

Domine ad adjuvandum (5 - Martin Fabri), (4), (4)

Et cum Spiritu tuo / Und mit deinem Geist (4), (4)

Lob und Preis sei dir / Sláva tobě Hospodine (4)

Und mit deinem Geist / I s duchem tvým svatým (4)

Amen Amen Amen / Und mit deinem Geist / I s duchem tvým svatým (4 - Karl Otto Stangen)

Habemus ad Dominum / Das haben wir zu dem Herren (4)

Ordinarium-Paraphrasen

$O$ Vater der Barmherzigkeit, Brunn (4)

Allein Gott in der Höh sei Ehr (4 - Gesius), (4)

Hosianna, Hosianna, dem Sohne David (4) 


\section{Hymnen}

Conditor alme syderum / Herr Gott und Schöpfer aller Ding (4 - Gesius)

Nun komm der Heiden Heiland (4), (5 - Eccard)

Veni redemptor gentium (4 - Gesius)

Christum wir sollen loben schon (4 - bruchstückhaft)

Fit porta Christi pervia / Christi Geburt ist offenbar / Stala se jest vec predivná (4)

Puer natus in Bethlehem (4), (4)

Puer natus... hoc in anno / Ein Kind geborn... / Dětátko se narodilo, v tomto roce (4 - bruchstückhaft)

Parvulus nobis nascitur / Uns ist ein Kindlein heüt geborn (4), (4)

In hymnis et confessionibus (Dies absoluti, praeterunt) / Es ist jetzund die Zeit ${ }^{20}$ (4 - Goudimel, Ps. 8)

Christe qui lux es et dies / Christe der du bist Tag u. Licht (4 - Gesius)

Vita sanctorum decus angelorum / Der Heiligen leben, tut stets (4), (4)

Tu tuo laetos famulos trophaeo (4), (4)

Festum nunc celebre (5), (4)

Coelos ascendit hodie / Gen Himmel aufgefahren ist (4 - Gesius)

Veni Creator Spiritus, mentes / Komm Gott Schöpfer Heliger Geist (4)

Spiritus Sancti gratia / Des Heiligen Geistes reiche Gnad (4)

O lux beata Trinitas / Der du bist derei in Einigkeit (4 - M.Franck)

Trinitas sancta, unitasque (4)

Te Deum laudamus / Tě Boha chválime (5)

$\underline{\text { Sequenz }}$

Christ lag in Todes Banden (4 - Vulpius)

Magnificat

Meine Seel erhebt den Herren (5, Tonus 5), (4)

\section{Gesangbuch aus Smolnícka Huta}

Hymnen

Christe der du bist Tag und Licht (4)

\section{$\underline{\text { Sequenz }}$}

Christ lag in Todes Banden (4, bruchstückhaft)

\section{Gesangbuch von Nicolaus Simonides (1685)}

Hymnen

Christum wir sollen loben schon (4)

Conditor alme syderum / Herr Gott du Schöpfer aller Ding (4)

Christe der du bist Tag und Licht (4)

Coelos ascendit hodie (4)

Der du bist drei in Einigkeit (4 - M.Franck)

Dicimus grates tibi summe rerum (4)

Dieses Fest und Freude (4)

Ein Kind geborn zu Bethlehem (4)

Hostis Herodes impie / Was fürchst du Feind Herodes sehr (4)

Komm, Gott Schöpfer, Heiliger Geist (4)

Spiritus Sancti gratia (4)

Veni Redemptor gentium (4 - Gesius)

Vita Sanctorum decus angelorum (4)

20 Deutsche Übersetzung des lateinischen Hymnus Dies absoluti, praeterunt von Ambrosius Lam (1554-1600), lutherisch-evangelischer Priest von Kežmarok (Käsmark). Vgl. HULKOVÁ, 1988, op. cit., S. 40. 
Ordinarium-Paraphrase

Hosianna, Hosianna, dem Sohne David (5)

Vaterunser

Vater unser im Himmelreich (4)

Passion (Turbae)

Das Leiden unseres Herren Jesu Christi, wie es beschreibt der helige Evangelist Matthäus (4)

Gesangbuch von Matthias Kruczay

Hymnen

Christum wir sollen loben schon (4)

Herr Gott du Schöpfer aller Ding (4)

Crudelis Herodes Deum Regem (4)

Christe der du bist Tag und Licht (4)

Der du bist drei in Einigkeit (4 - M.Franck)

Ein Kind geborn zu Bethlehem (4)

Komm, Gott Schöpfer, Heiliger Geist (4)

$\underline{\text { Sequenz }}$

Christ lag in Todes Banden (4)

Ordinarium-Paraphrasen

Allein Gott in der Höh sei Ehr (4)

Hosianna, Hosianna, dem Sohne David (4)

Wir glauben all an einen Gott (4)

\section{Die Stil-Tendenzen}

Eine deutliche Stil-Differenzierung zwischen den Quellen der 1. Hälfte des 17. Jahrhunderts und derjenigen der 2. Hälfte des 17. Jahrhunderts bzw. vom Anfang des 18. Jahrhunderts ist kaum möglich, weil der Inhalt erwähnter zipser Chorbücher eher konservativ ist. Sie enthalten zum größten Teil mehrstimmige Kirchenlieder und liturgische Gesänge älterer Ursprung, also aus der 1. Hälfte des 17. Jahrhunderts, bezw. aus der Wende des 16. und 17. Jahrhunderts. Ein wichtiger Teil von dieser kleinen Kompositionen ist in den autorisierten deutschen mehrstimmigen gedruckten Kantionalen von Bartolomäus Gesius, Michael Praetorius und Johann Hermann Schein aus dem Beginn des 17. Jahrhunderts belegt. Mehrere Kompositionen wurden allgemein verbreitet, wie z. B. der sechsstimmige Choralsatz des Osterliedes Heut triumphieret Gottes Sohn von Seth Calvisius. Dieser Choralsatz ist in unseren Quellen nicht nur mit dem deutschen Text (sowohl im Kantional von Banská Bystrica als auch in den späteren zipser Chorbüchern), sonder auch mit ungarischem Text (Ma Christus gyözedelmes lött in dem Gradual von Prešov) und mit tschechischem Text (Vstalt' jest dnes im Gesangbuch von Hôrka) erhalten. ${ }^{21}$ Die Paraphrase des Vaterunsers in der Resposorial-Form (Lithanei), welche

21 HULKOVÁ, 2018, op. cit., S. 532-533. 
im Agend Büchlein von Veit erwähnt ist, wurde nicht nur in den deutschen Gemeinden üblich. Solche Paraphrase im Wechselgesang „Pueri - Chorus“ kommt mit ungarischem Text in Gradual von Prešov vor. Man kann sie mit dem tschechischen Text Otče náš nebeský - Tebet' vzýváme tvé dítky bereits in der sgn. Agende von Banská Bystrica (1585) finden. Zwar sind in dieser älteren Quele die vierstimmige Chor-Sätze mit manchen Fehlern notiert, man kann aber diesen ältesten Beweis des einfachen polyphonischen Kirchengesangs in der slowakischen Gemeinde dank der Vergleichung mit den ungarischen Sätzen aus dem Gradual von Prešov rekonstruieren. ${ }^{22}$

Die Stil-Entwicklung im mitteleuropäischen mehrstimmigen Kirchengesang hat sich in der 2. Hälfte des 16. Jahrhundert im Grunde in zwei Hauptlinien aufgeteilt. Erste Linie stellt die durchkomponierte, meist vier bis achtstimmige Choral- bzw. Liedmotette mit polyphon geführeten Stimmen dar und ist z.B. mit den representativen Werken von Johannes Eccard, Leonhard Lechner oder Michael Praetorius vertreten. ${ }^{23}$ Zweite Linie ist ein einfacher vier- bis sechsstimmiger Choralsatz mit statischem, homorhytmischen Verlauf. Den Vorbild solcher Choralsätze kann man in den für die Schulen geeigneten metrischen Hymnen oder in den allgemein verbreiteten vierstimmigen Fassungen der genfer Psalmen von Claude Goudimel finden. In beiden Linien haben die Komponisten um die Wende des 16. und 17. Jahrhunderts den Cantus firmus in Discantus gesetzt.

Wenn wir den Inhalt der oberungarischen handschriftlichen Quellen in Betracht ziehen, so sind hier beide Linien vertreten. Deutsche Liedmotetten kommen z.B. in einigen Handschriften der Musikaliensammlung von Bardejov (Bartfeld) relativ häufig vor. In der Handschrift Ms. Mus. Bártfa 18 ist sogar die Choralmotette Nun bitten wir den heligen Geist von Michael Praetorius mit dem tschechischen Text Poprosmež my Ducha svatého zu finden. ${ }^{24}$ Für die heimische Kantoren und Organisten war also Liedmotette in der 1. Hälfte des 17. Jahrhunderts eine wohlbekannte Gattung des Kirchengesangs. Kein Wunder, daß auch die bedeutendste oberungarische Komponisten jener Zeit, Johannes Schimrack und Zacharias Zarewutius solche Werke komponiert haben. ${ }^{25}$ Unter den Musikstücken, die in den erhaltenen Chorbüchern erhalten sind, kann man jedoch

22 In der älteren musikwissenschaftlichen Literatur wurde diese Lithanei als unrekonstruierbar angesehen. Vgl. HUDEC, 1941, op. cit., S. 61.

23 Vgl. BRUSNIAK, Friedhelm. Anmerkungen zur „Liedmotette“ im 16. Jahrhundert. In Tradition in der mitteldeutschen Musik des 16. Jahrhundert. Symposiumsbericht. Gottingen 1997. Gottingen: Vandenhoeck and Ruprecht, 1999, S. 30.

24 MURÁNYI, Róbert Árpád. Thematisches Verzeichnis der Musiksammlung von Bartfeld (Bártfa). Deutsche Musik in Osten 2. Bonn: Gudrun Schröder, 1991, Nr. 1271.

25 Es sind uns vier achtstimmige Choralmotetten von Johann Schimrack, dem Organisten aus Spišské Podhradie/Kirchdrauf erhalten: „Christ lag in Todesbanden“, „Der Tag der ist so freudenreich“, „Heutt triumphieret Gottes Sohn“ und „Nun komm der Heiden Heiland“. Vgl. PETŐCZOVÁ, Janka. Johann Schimrack / Ján Šimrák - spišský polyfonik 17. storočia [Johann Schimrack - ein zipser Polyphoniker aus dem 17. Jahrhundert]. In Musica Scepusii Veteris. Konferenzbericht. Bratislava - Prešov: Ústav hudobnej vedy SAV, Prešovský hudobný spolok Súzvuk, 2008, S. 89-90. Von Zacharias Zarewutius, Organist zu Bardejov/Bartfeld sind uns ähnliche Kompositionen in den Handschriften Ms. Mus Bártfa 21 und 26 der Musikaliensammlung von Bartfeld erhalten, u. zw. achtstimmige Choralmotetten „Ach Christe Jesu Kindelein“, „Da Jesus geboren war“, „Der Tag der ist so freudenreich“, „Das alte Jahr vergangen ist“, „Nur bitten wir den heiligen Geist“. Vgl. MURÁNYI, Róbert Árpád (ed.). Zacharias Zarewutius: Magnificats and Motets. Musicalia Danubiana 8. Budapest: MTA Zenedudományi Intézet, 1987. 
keine Liedmotetten im vollen Sinne des Wortes finden. Einige Kompositionen können etwa der Choralmotette mit einfachem polyphonen, vom Cantus firmus abgeleiteten Satz entsprechen. ${ }^{26}$ Einen interessanten Stück dieser Art stellt das fünfstimmige lateinisch-tschechische Te Deum mit dem choralen Cantus firmus im Tenor von einem unbekannten Author im Gesangbuch aus Lubica dar. ${ }^{27}$

\section{Die Kirchenlieder heimischer Herkunft}

Es gibt im ganzen Repertoire der erwähnten Chobücher von ca. mehrstimmiger 300 Stücke etwa 50 Kirchenlieder, meist mit deutschem, manchmal mit ungarischem oder tschechischem Text, die in den Quellen außer Ungarn nicht vorkommen. Ihre Autoren sind fast ausschließlich unbekannt. Es handelte sich zum Teil um das regional verbreitete Repertoire, das am mehreren Orten der Zips und Scharosch gemeinsam war und in verschiedenen Handschriften in fast identischen, manchmal auch variierten Fassungen vorkommt. Die Autoren von dieser anonymen Stücke waren wahrscheinlich lokale Kantoren, die einfache Choralsätze komponierten, aber dabei auch den Stil von bekannten Komponisten nachzuahmen versuchten. Ein Versuch um eine Komposition, die an Choralmotette erinnert, stellt das vierstimmige Weinachtscantio in der tschechischen Sprache Nastal nám den veselý (Nobis est natus hodie) aus dem Gesangbuch von Lubica dar. ${ }^{28}$

Die einzige bekannte Komposition von gewissen Andreas F. de Hethars ist das einfache vierstimmige Begäbnis-Lied Zu dir o Herr Gott alleine. (Abb. 1) Das Lied ist in drei zipser Chorbücher erhalten - in dem Gesangbuch von Lubica (als Generalbaßlied) wo auch der Name des Verfassers geschrieben ist, in dem Gesangbuch von Nicolaus Simonides von Velká (als vierstimmiger Chorsatz) und in dem Kruczay-Gesangbuch (als vierstimmiger Chorsatz). Es ist bemerkenswert, daß einige Stücke von den zipser Chorbüchern aus den siebenbürgischen handschriftlichen Chorbücher des 17. Jahrhunderts bekannt sind, wie z. B. die vierstimmige Kirchenlieder Jauchzet dem Herren alle Lande, Jerusalem beweinet sehr, Heut ist gefahrn der Herre Christ, O Herre Jesu Christ, mein höchster Trost auf Erden, O Herre Gott straf mich nicht in deinem Zorn. ${ }^{29}$

Die anonyme Stücke aus den zipser Handschirften kann man nicht nur als einfache Choralsätze beschreiben. Es sind hier zwei verschiedene Typen des Choralsatzes - außer

26 Ibid., S. 28-29.

27 RUŠČIN, Peter (ed.). Te Deum laudamus / Te Boha chwalime for 5 Voices: Lubica Hymnal (17th cent.). Musicalia Istropolitana 4. Bratislava: STIMUL, 2011.

28 Vgl. RYBARIČ, Richard. Dejiny hudobnej kultúry na Slovensku I. Stredovek, renesancia, barok [Die Geschichte der Musikkultur in der Slowakei I. Mittelalter, Renaissance, Barock]. Bratislava: Opus, 1984, S. 197-198; RUŠČIN, Peter. K hudobno-textovej interpretácii piesne Nastal nám den veselý z Lubického spevníka. [Zur Musik-Text-Interpretation des Liedes „Nastal nám den veselý“ aus dem Gesangbuch aus Lubica.] In Slovo a hudba ako štrukturálno-architektonický celok hudobného myslenia 17.-18. storočia [Wort und Musik als strukturell-architektonische Ganzheit des Musikdenkens im 17. und 18. Jahrhundert]. Konferenzbericht. Prešov: Súzvuk, 2006, S. 177-190.

29 SZŐCS, Tamás. Kirchenlied zwischen Pest und Stadtbrand: Das Kronstadter Kantional I.F.78 aus dem 17. Jahrhundert. Köln - Weimar - Wien: Böhlau, 2009, S. 153-155, 183, 216, 240-241. 
mehrstrophigen Homophonen Kirchenlieder auch die Sätze, in denen die homophone und polyphone Abschnitte wechseln. Diesen zweiten Typus wird oft bei einstrophigen oder zweistrophigen, manchmal sogar bei den prosaischen Texten (wie z.B. in den Motetten) verwendet. Die einzelne Text-Abschnitte werden oft wiederholt, einzelne Worte können zwischen den Stimmen imitiert oder rhetorisch wiederholt werden. (Abb. 2) Die Polyphonie ist hier gelegentlich, z.B. bei Melismen, besonders in Kadenzen, oder am Anfang der Komposition (bei verspäteten Eintritt einiger Stimmen) verwendet. Manchmal kommt auch Metrum-Wechsel dazu. Es scheint, daß dieses Kompositionsprinzip zu ähnlichem Kontrast und Diferenzierung führt, welches für die Mehrchörigkeit oder konzertaten Stil des Frühbarocks typisch ist.

Die Einflüsse der cori spezzati-Technik sind allerdings auch beim einfachen Choralsatz wahrscheinlisch heimischer Herkunft zu finden, wie es z. B. beim Kirchenlied Freuet euch in dem Herren aus dem Gesangbuch von Nicolaus Simonides der Fall ist. (Abb. 3) Die einstimmige Version (discantus) des Liedes Freuet euch in dem Herren ist aus der 8. Auflage von Cithara Sanctorum (Leutschau 1684) mit dem tschechischen Text „Spívejte Hospodinu“ bekannt. Es ist interessant, daß der tschechische Text des Liedes bereits in der gedruckten Katechismus-Ausgabe von Daniel Pribiš aus dem Jahr 1634 mit dem titel „Ein kurzes Lied nach dem Katechismus oder nach der Predigt zu singen“ erschien. Das Lied wurde wahrscheinlich schon damals auf dieselbe Weise gesungen, welche 50 Jahre später in Cithara Sanctorum und als Diskant-Stimme des fünfstimmigen Kirchenliedes Freuet euch in dem Herren im Chorbuch von Nicolaus Simonides vorkommt.

Eine jüngere Stilschicht stellen die Kirchenlieder mit Generalbaß dar, die in den zipser Chorbüchern der 2. Hälfte des 17. Jahrhunderts entweder als Cantus mit Baß, oder manchmal als Trio-Satz geschrieben sind. Die Baß-Stimme bei den dreistimmigen Gesängen ist nur selten beziffert. Manchmal handelt es sich um die spätere, mit anderen Händen geschriebene Eintragungen. Auch hier sind neben der deutschen Kirchenlieder des Mittelbarocks auch heimische Kirchenlieder, wie Pfingstlied Ihr Himmel jauchzet heute von Christoph Klesch, oder das deutsche Lied Ach, ich betrübte Mutter, ach! - eine anonyme Übersetzung des slowakischen Planctus Ach já matka zarmúcená von Cithara Sanctorum. ${ }^{30}$

Das mehrstimmige, meist vier-, seltener fünf- bzw. sechsstimmige Kirchengesang, manchmal für die Schulchöre geeignet (der Satz um die Quarte höher transponiert), blieb wahrscheinlich bis zu Ende des 17. Jahrhunderts eine der üblichen Formen des liturgischen Gesangs in den evangelischen Gemeinden oberungarischer Städte. Diese Praxis wurde auch von der mehrchörigen cori-spezzati-Technik aus der frühbarocken Kirchenmusik beeinflusst. Das einstimmige bzw. zweistimmige Kirchengesang mit Generalbass hat den mehrstimmigen liturgischen Gesang in der 2. Hälfte des 17. Jahrhunderts noch nicht ersetzt, obwohl auch Generalbaßlieder in den oberungarischen Handschriften des 17. Jahrhunderts vorkommen. Der Inhalt des Kruczay-Gesangbuchs deutet an, daß man in den kleineren zipser Städte noch zu Beginn des 18. Jahrunderts

30 Vgl. RUŠČIN, Peter (ed.). Nicolaus Simonides - Himmlischer Engel=Schall, oder Gesangbuch (1685): Auswahl der Kirchenlieder und Liedmotetten. Prešov - Bratislava: Ústav hudobnej vedy SAV, Prešovský hudobný spolok Súzvuk, 2015, S. 44-45, 62-63, 70, 92-93. 
neben den Generalbaßliedern weiterhin die mehrstimmige Kirchenlieder in der Form des beiden erwähnten Typen von Choralsatzes gepflegt hat.

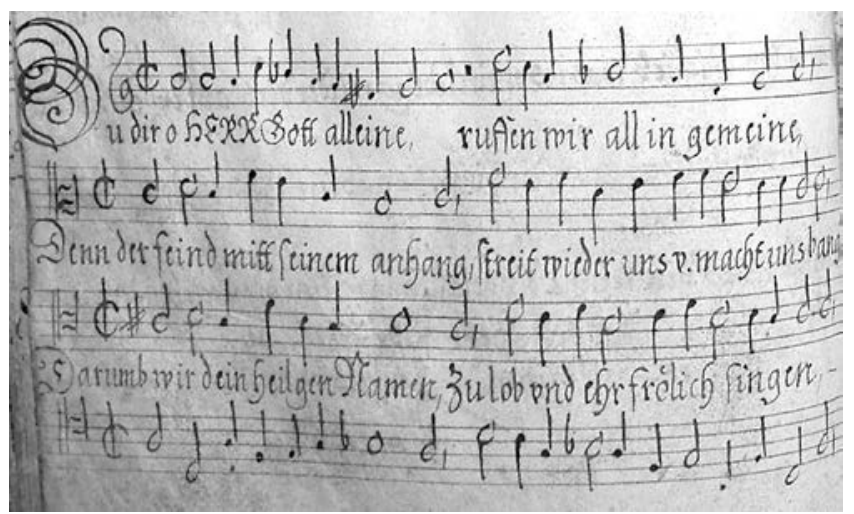

Abb. 1 Der Anfang des Begräbnis-Liedes Zu dir o Herr Gott alleine im Gesangbuch von Nicolaus Simonides (1685)

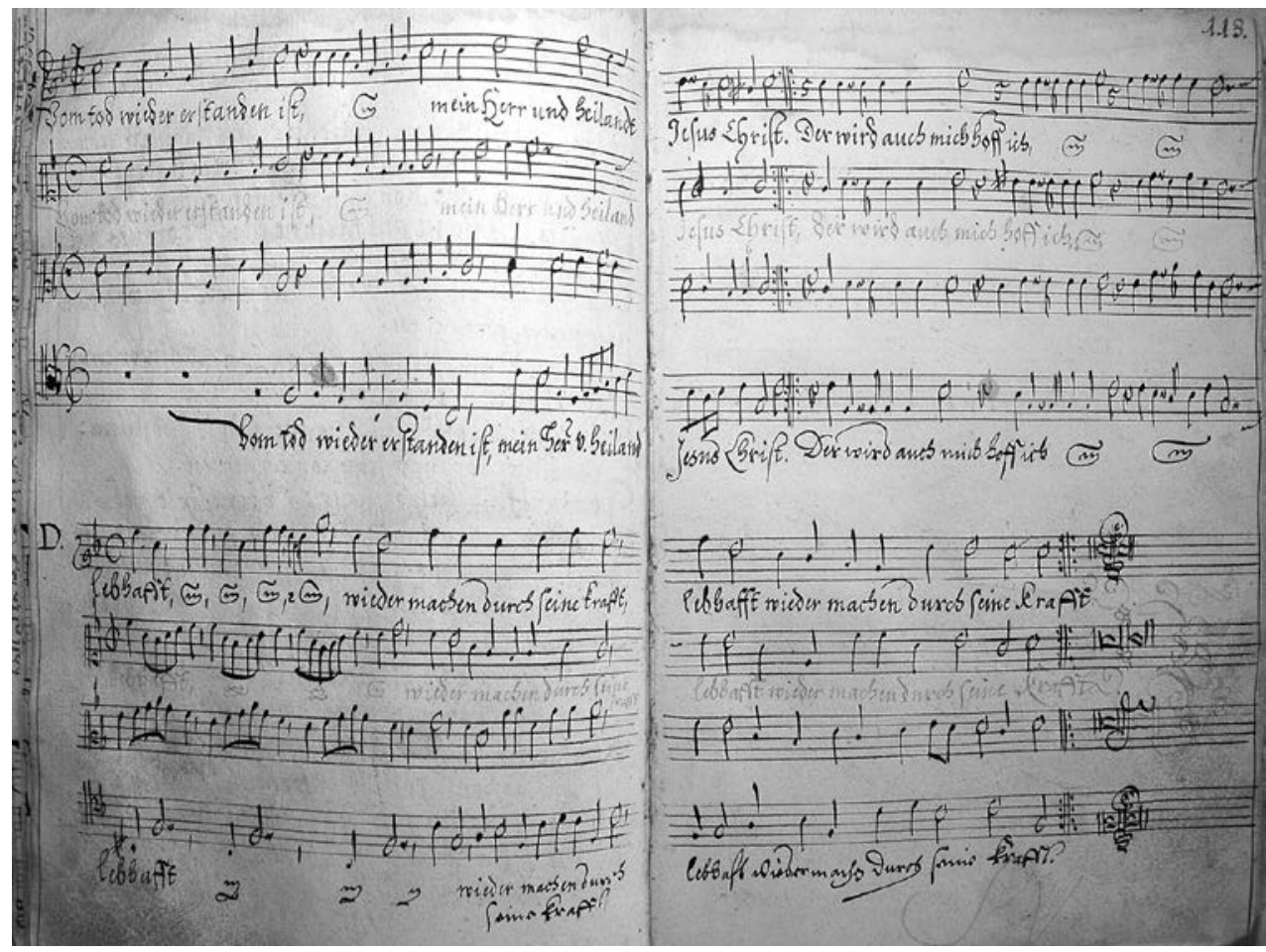

Abb. 2 Die Choral-Motette Vom Tod wieder erstanden ist im Gesangbuch von Nicolaus Simonides (1685) 


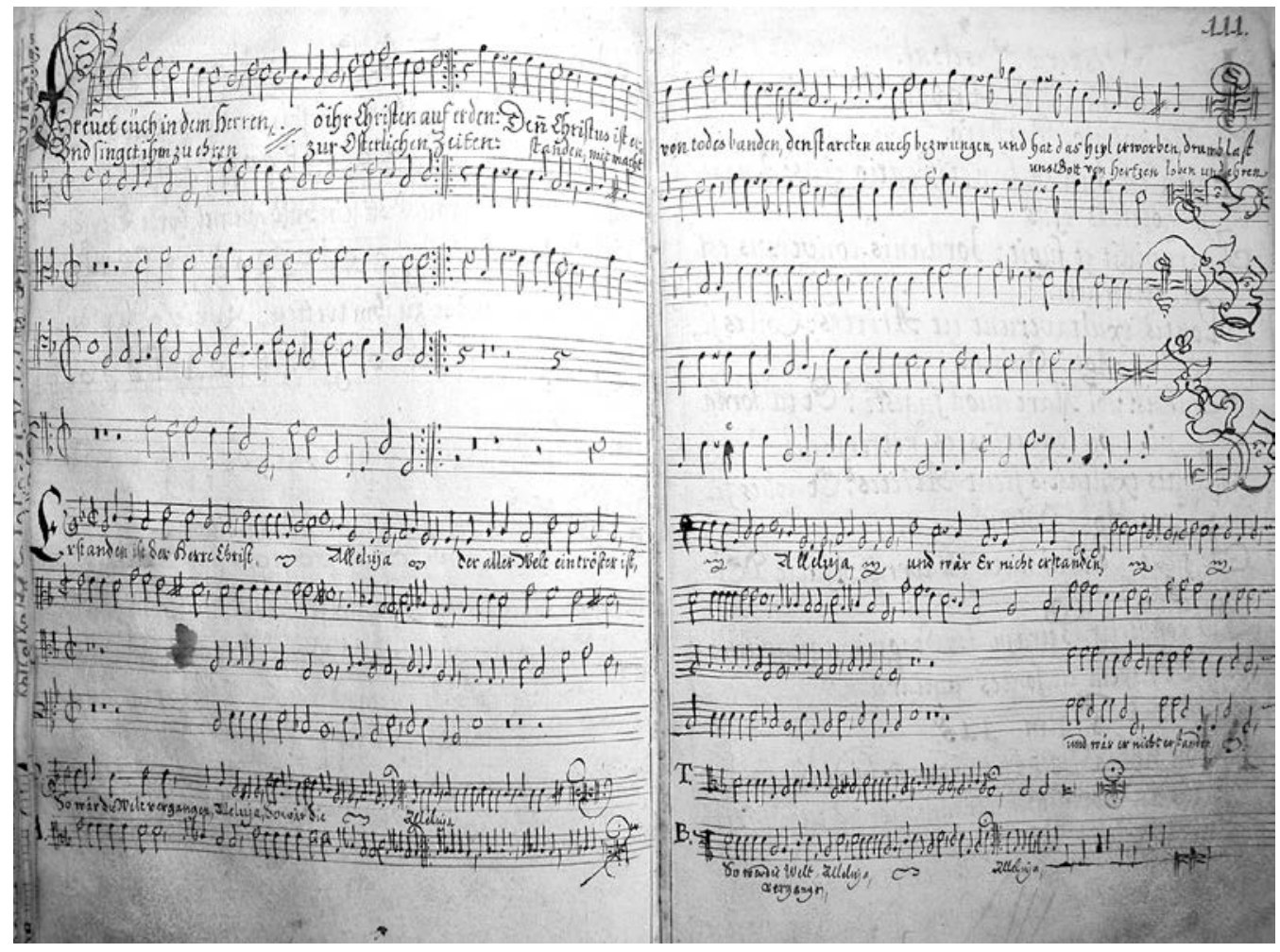

Abb. 3 Der Choral-Satz Freuet euch in dem Herren im Gesangbuch von Nicolaus Simonides (1685)

\section{Bibliography}

\section{Sources}

Die Agende von Banská Bystrica. SK-BRl, BB 663.

Das Kantional von Banská Bystrica. H-Bev, R 1644.

Das Gradual von Prešov (Eperjes). H-Bn, Fol. Hung. 2153.

Das Gesangbuch von Hôrka (St. Andreas). SK-BRnm, sine sign.

Das Gesangbuch aus Lubica. SK-BRnm, MUS XVIII 652.

Das Gesangbuch aus Smolnicka Huta. SK-BRnm, MUS I 354.

Das Gesangbuch von Nicolaus Simonides. SK-Evanjelický a.v. farský úrad Poprad-Velká, sine sign.

Das Gesanguch von Matthias Kruczay. BRsav, B 97 (microfilm). 


\section{Literature}

BRUSNIAK, Friedhelm. Anmerkungen zur „Liedmotette“ im 16. Jahrhundert. In Tradition in der mitteldeutschen Musik des 16. Jahrhundert. Symposiumsbericht. Gottingen 1997. Gottingen: Vandenhoeck and Ruprecht, 1999, S. 27-36.

FERENCZI, Ilona (ed.). Graduale Ecclesiae Hungaricae Epperiensis 1635. Musicalia Danubiana 9. Budapest: Magyar Tudományos Akadémia Zenetudományi Intézet, 1988.

FERENCZI, Ilona. A bestercebányai kancionálé (1623). In MÁNYOKI, János - PINTER, Gábor (eds.). BIVIO Tanulmányok az Evangélikus Országos Könyvtár múhelyéból 2018. Budapest: Evangélikus Országos Gyüjtemény, 2018, s. 20-47.

FERENCZI, Ilona - HULKOVÁ, Marta. Gemeinsame ein- und mehrstimmige Stücke in dem Gradual von Eperjes und in dem Gesangbuch aus Lubica. Studia Musicologica Academiae Scientiarum Hungaricae, 22, 1980, S. 345-396.

HUDEC, Konštantín. Hudba v Banskej Bystrici do 19. storočia. Liptovský Sv. Mikuláš: Tranoscius, 1941.

HULKOVÁ, Marta. Lubický spevník. Musicologica Slovaca, 12, 1988, S. 21-102.

HULKOVÁ, Marta. Evangelische handschriftliche Gesangbücher aus der Spiš (Zips) von der Wende des 17. und 18. Jahrhunderts. In Gegenreformation und Barock in Mitteleuropa / in der Slowakei. Konferenzbericht. Bratislava: Kabinet für Slawistik der SAW, 2000, S. 239-250.

HULKOVÁ, Marta. Spevník z Hôrky a spišské rukopisné spevníky zo 17. a 18. storočia. In Ad honorem Richard Rybarič. Zbornik z muzikologickej konferencie Musicologica historica I. Bratislava: Ústav hudobnej vedy SAV, 2011, S. 87-101.

HULKOVÁ, Marta. Konfesijné zmeny v 16. storočí v Európe a ich vplyv na cirkevnú hudbu na území Slovenska. In BUZÁSSYOVÁ, L'udmila - JURÍKOVÁ, Erika - GRUSKOVÁ, Jana (eds.). Ideológia v premenách času v pamiatkach gréckej a latinskej tradície. Bratislava: Univerzita Komenského v Bratislave, 2018, S. 204-216.

MATÚŠ, František. Zachariáš Zarevúcky - životné osudy. In Zachariáš Zarevúcky (Zarevutius). 400 rokov od narodenia organistu a skladatela. Zborník z konferencie. Prešov: Prešovský hudobný spolok Súzvuk, 2005, S. 67-84.

MURÁNYI, Róbert Árpád. Thematisches Verzeichnis der Musiksammlung von Bartfeld (Bártfa). Deutsche Musik in Osten 2. Bonn: Gudrun Schröder, 1991.

MURÁNYI, Róbert Árpád (ed.). Zacharias Zarewutius: Magnificats and Motets. Musicalia Danubiana 8. Budapest: MTA Zenetudományi Intézet, 1987.

PETŐCZOVÁ, Janka. Johann Schimrack / Ján Šimrák - spišský polyfonik 17. storočia. In Musica Scepusii Veteris. Konferenzbericht. Bratislava - Prešov: Ústav hudobnej vedy SAV, Prešovský hudobný spolok Súzvuk, 2008.

PETÓCZOVÁ, Janka. Hudba ako kultúrny fenomén v dejinách Spiša. Bratislava: Ústav hudobnej vedy SAV - Prešovský hudobný spolok Súzvuk, 2014.

RIEDEL, Friedrich W. Lutherischer Gottesdienst und katholische Kirchenmusik. In Gegenreformation und Barock in Mitteleuropa / in der Slowakei. Konferenzbericht. Bratislava: Kabinet für Slawistik der SAW, 2000, S. 59-80.

RUŠČIN, Peter. Repertoár Kruczayho spevníka v stredoeurópskom kontexte. In Štýlotvorné prvky vo vokálnej a inštrumentálnej hudbe 16.-18. storočia. Zborník z konferencie. Prešov: Prešovský hudobný spolok Súzvuk, 2003, S. 63-79.

RUŠČIN, Peter. K hudobno-textovej interpretácii piesne Nastal nám den veselý z Lubického spevníka. In Slovo a hudba ako štrukturálno-architektonický celok hudobného myslenia 17.-18. storočia. Zborník z konferencie. Prešov: Súzvuk, 2006, S. 177-190. 
RUŠČIN, Peter (ed.). Te Deum laudamus / Te Boha chwalime for 5 Voices: Lubica Hymnal (17th cent.). Musicalia Istropolitana 4. Bratislava: STIMUL, 2011.

RUŠČIN, Peter (ed.). Nicolaus Simonides - Himmlischer Engel=Schall, oder Gesangbuch (1685): Auswahl der Kirchenlieder und Liedmotetten. Prešov - Bratislava: Ústav hudobnej vedy SAV, Prešovský hudobný spolok Súzvuk, 2015.

RUŠČIN, Peter. Die Kirchenlieder aus dem handschriftlichen Gesangbuch Himmlischer Engel-Schall (1685) von Nicolaus Simonides. In PETÓCZOVÁ, Janka (ed.). The Musical Sources of Spiš / Zips and Central Europe. Bratislava: Ústav hudobnej vedy SAV, 2018, S. 60-95.

RYBARIČ, Richard. Dejiny hudobnej kultúry na Slovensku I. Stredovek, renesancia, barok. Bratislava: Opus, 1984.

SZŐCS, Tamás. Kirchenlied zwischen Pest und Stadtbrand: Das Kronstadter Kantional I.F.78 aus dem 17. Jahrhundert. Köln - Weimar - Wien: Böhlau, 2009. 